\title{
SPEED SENSOR FAULTS DIAGNOSIS IN AN INDUCTION MOTOR VECTOR CONTROLLED DRIVE
}

\author{
Mohamed BOUAKOURA*, Nasreddine NAÏT-SAÏD ${ }^{* *}$, Mohamed-Said NAÏT-SAÏD ${ }^{* * *}$ \\ LSP-IE Laboratory, Electrical Engineering Department, Faculty of Technology, University of Batna 2, \\ 05000 Batna, Algeria, ${ }^{*}$ Tel.: +213 560365608, *E-mail: bouakouramohamed@gmail.com \\ ${ }^{* *}$ Tel.: +213 55929 2164, ${ }^{* *}$ E-mail: n_naitsaid@yahoo.com \\ ${ }^{* * *}$ Tel.: +213 77368 8980, ${ }^{* * *}$ E-mail: medsnaitsaid@yahoo.fr
}

\begin{abstract}
Many induction motor speed controllers contain a speed or position sensor. This last is required to provide accurate measurement. A faulty speed sensor decreases the controller performance dramatically. Hence, a fault diagnosis and detection technique is necessary. This paper deals with several faults which affect the speed sensor used in an induction motor vector controlled drive. Three different faults are considered; offset fault, uncertainty of measurement, and total loss of feedback information. Then a detection strategy is suggested based on the computation of the energy of the average standard deviation of speed data. Simulation on Matlab/Simulink and experiments were carried out to show the effect of each fault on the vector control performance and to verify the effectiveness of the proposed detection scheme.
\end{abstract}

Keywords: speed sensor fault, induction motor, field oriented control, average standard deviation, energy of a signal

\section{INTRODUCTION}

Sensors are devices that transform a physical signal to an electrical one (usually a current or voltage). The use of these elements is unavoidable in most engineering applications, especially for monitoring and control. They provide calculators with the necessary data for decision making. In different fields, such as industry and transportation, having reliable sensors is mandatory. However, these sensors are prone to many faults, which may affect the system performance. Usually, speed control requires speed or position sensors. In induction machine vector control schemes, the accuracy of the speed sensor signal is crucial. This component may undergo several faults which can be listed in four major types as follows:

- Constant faults in which the sensor's signal remains constant despite the variation of the rotor position $[1,2]$.

- Bias, offset and excessive noise due to measurement considered as additional faults [212].

- Gain fault where the encoder signal is amplified [13].

- Intermittent or total loss of feedback information [14-24].

In tachometric sensors, either DC generators or alternators, the intermittent fault is usually due to rotor eccentricity $[15,25]$ or attrition of the brushes or bearings. Whereas the variation of electrical parameters, such as resistances and inductances, in some operating conditions produces offset faults. Note that, the loss of feedback signal may occur due to electrical link disconnection or the breakdown of the sensor. Besides, the weakness of the light source (LED) or the degradation of the phototransistor in rotary encoders causes uncertain measurements [2, 15]. In both types of sensors, the mechanical sliding of the encoder can also cause an inaccuracy of measurement. Such faults do not cause an immediate change in average speed, but a significant change in its standard deviation [23].
Some experts designed robust encoders with the ability to maintain acceptable functionality despite their faulty state [26]. Yet, more researches are being conducted to detect and isolate speed sensor faults. The classical way to detect any malfunction implies hardware redundancy [27], so the signals of the faulty sensors and the healthy ones are compared to generate fault indicators. But since the advent of electronic calculators, model based methods gained more interest. This brought forward the concept of analytical redundancy where virtual sensors (estimators, filters, observers) such as Kalman filter, Luenberger observer and MRAS estimate the speed signal from other available measurements $[1-5,8-15,17-20,22,28-30]$. Moreover, two recent sets of techniques have been developed. The first one is based on signal processing, such as wavelet packet decomposition $[15,31][15,35]$, hodographs [32], adaptive thresholds [33], least squares regression [6], parity space [21] and average standard deviation [23]. The second one involves machine learning techniques such as fuzzy logic [34, 35], artificial neural networks [24] and genetic algorithms [32].

This paper investigates the effect of speed sensor faults on the induction machine control, and then it suggests a new detection approach. The advantage of this last resides in its low cost, simplicity of implementation and efficiency. The paper is organized as follows. Firstly, an introduction presenting a literature review on the subject. Section two is dedicated to field oriented control of the induction motor. Three speed sensor faults are explained in section three. Simulation results are shown in section four, while a detection technique is suggested in the fifth section. The experimental results of speed sensor faults and their detection are shown in section six. At last, a conclusion is presented in section seven.

\section{INDIRECT FIELD ORIENTED CONTROL OF THE INDUCTION MOTOR}

Vector control by rotor flux orientation is a widely used and an effective technique. Its aim is the separate 
regulation of torque and rotor flux similarly to the independently excited DC motor. To achieve this purpose, "d" axis is fixed to the rotor flux so $\boldsymbol{\phi}_{r q}$ becomes null. The induction machine model after flux orientation is given below:

$$
\left\{\begin{array}{l}
\phi_{r}=\phi_{r d}=L_{r} i_{r d}+L_{m} i_{s d} \rightarrow i_{r d}=\frac{1}{L_{r}}\left(\phi_{r d}-L_{m} i_{s d}\right) \\
\phi_{r q}=0=L_{r} i_{r q}+L_{m} i_{s q} \rightarrow i_{r q}=-\frac{L_{m} i_{s q}}{L_{r}} \\
v_{s d}=R_{s} i_{s d}+\sigma L_{s} \frac{d}{d t} i_{s d}+\frac{L_{m}}{L_{r}} \frac{d}{d t} \phi_{r}-\omega_{e} \sigma L_{s} i_{s q} \\
v_{s q}=R_{s} i_{s q}+\sigma L_{s} \frac{d}{d t} i_{s q}+\omega_{e}\left(\frac{L_{m}}{L_{r}} \phi_{r}+\sigma L_{s} i_{s d}\right) \\
v_{r d}=0=R_{r} i_{r d}+\frac{d}{d t} \phi_{r} \rightarrow \tau_{r} \frac{d}{d t} \phi_{r}+\phi_{r}=L_{m} i_{s d} \\
v_{r q}=0=R_{r} i_{r q}+\omega_{s l} \phi_{r} \rightarrow \omega_{s l}=\frac{L_{m}}{\tau_{r} \phi_{r}} i_{s q} \\
T_{e}=p \frac{L_{m}}{L_{r}} \phi_{r d} I_{s q}
\end{array}\right.
$$

We notice from the model that there's a coupling between the stator voltages and currents. In other words, we cannot control the two currents $i_{s d}$ and $i_{s q}$ independently. Thus, we have to eliminate the coupling terms $e_{d}$ and $e_{q}$. These two are formulated respectively by the equations (2) and (3).

$e_{d}=\omega_{e}\left(\frac{L_{m}}{L_{r}} \phi_{r}+\sigma L_{s} i_{s d}\right)$

$e_{q}=\frac{L_{m}}{L_{r}} \frac{d}{d t} \phi_{r}-\omega_{e} \sigma L_{s} i_{s q}$

So the stator equations become as follows:

$v_{s d}^{*}=R_{s} i_{s d}+\sigma L_{s} \frac{d}{d t} i_{s d}$

$v_{s q}^{*}=R_{s} i_{s q}+\sigma L_{s} \frac{d}{d t} i_{s q}$

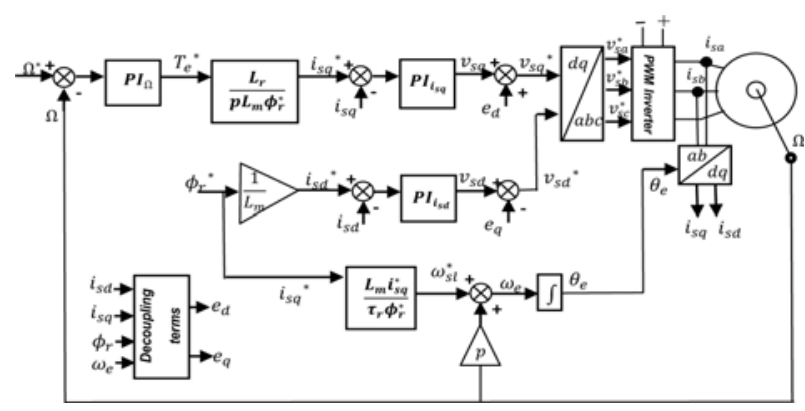

Fig. 1 Block scheme of the indirect field oriented control

Rotor flux and torque are controlled indirectly by $i_{s d}$ and $i_{s q}$ currents. $i_{s d}^{*}$ is a steady component because its value is set and determined from the rotor flux reference. While $i_{s q}^{*}$ is obtained from torque reference which is the output of the PI speed controller. The slip frequency is estimated from $\phi_{r}$ and $i_{s q}$ then summed with the rotor electric speed to get the synchronous frequency.

The block scheme of the indirect field oriented control is depicted in Fig. 1.

\section{SPEED SENSOR FAULTS}

\subsection{Offset Fault}

An offset fault represents a constant shift between the actual speed and its value measured by the sensor. This fault is simulated by adding a constant positive value to the speed so $\Omega_{F}=\Omega+\Delta \Omega$.

The speed control loop becomes as shown on Fig. 2 .

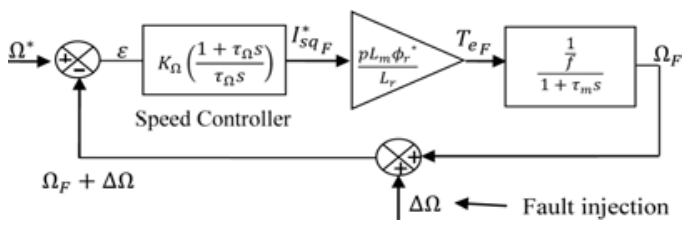

Fig. 2 Block scheme of speed control loop with a speed sensor fault

\subsection{Uncertain Measurement Fault}

This fault is performed on Matlab by adding a random value to the measured speed, so $\widetilde{\Omega_{F}}=\Omega_{\text {healthy }}+|\Delta \Omega|$. Then the expression of the actual speed becomes as follows:

$\Omega_{F}=\frac{\gamma \Omega^{*}}{1+\gamma}-\frac{\gamma|\Delta \Omega|}{1+\gamma}$

Where:

$\gamma=K_{\Omega}\left(\frac{1+\tau_{\Omega} \boldsymbol{s}}{\boldsymbol{\tau}_{\Omega} \boldsymbol{s}}\right)\left(\frac{p L_{m} \phi_{r}^{*}}{L_{r}}\right)\left(\frac{\frac{1}{f}}{1+\tau_{\boldsymbol{m}} \boldsymbol{s}}\right)$

\subsection{Zero Feedback Fault}

This fault is the most dangerous because the sensor stops functioning and gives no output signals. This occurs suddenly and in a very short time where " $\tau_{\text {Fault }}$ is smaller than the mechanical time constant $\tau_{\text {Fault }}<\tau_{\text {Mec }}$ [23]. On Matlab, the simulation is simply done by multiplying the speed by zero.

\section{SIMULATION RESULTS AND DISCUSSION}

To show the influence of the mentioned faults on the control technique, a simulation has been performed on Matlab, where each fault is activated at $\mathrm{t}=11 \mathrm{~s}$. Fig. 3a), $3 b), 3 c)$, and 3d) represent successively; The phase current, the three phase currents on "dq" reference frame, the torque and the rotor speed.

The motor prompts an inrush current when the reference speed goes from zero to $100 \mathrm{rad} / \mathrm{s}$, then it keeps the same amplitude. Speed controller incites more current to cancel the effect of the offset fault once it is applied. So the magnitude of the phase currents rises, hence, the same is noticed when they are transformed to the synchronous reference frame. The torque is and image of the $I_{s q}$ current, thus it behaves the same way. The actual speed decreases by $10 \mathrm{rad} / \mathrm{s}$ to compensate the effect of the sensor fault.

Since the uncertainty of measurement fault is intermittent, it causes pulsation of machine variables. 
The phase current manifests many fluctuations (Fig. $3 a)$ ). The fault effect is more noticeable on $I_{s q}$ current and torque, while the actual speed pulsates and doesn't follow its reference perfectly. Zero feedback fault is the most severe. The increasing of phase current results the torque and speed to rise. $I_{s q}$ current is limited between $-6 \mathrm{~A}$ and 6 A so the speed doesn't diverge to a high value.

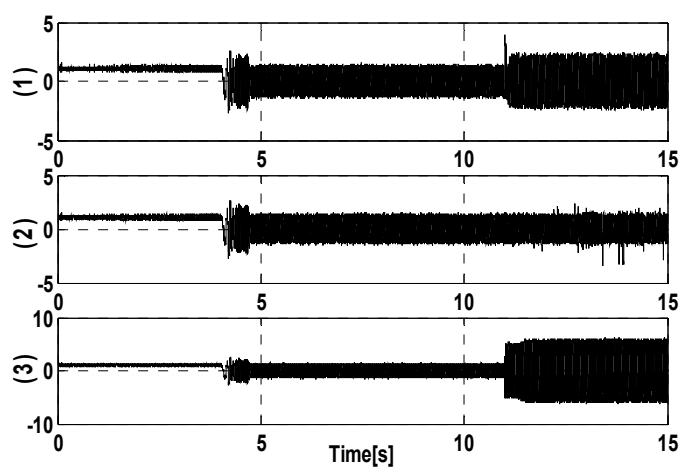

a)

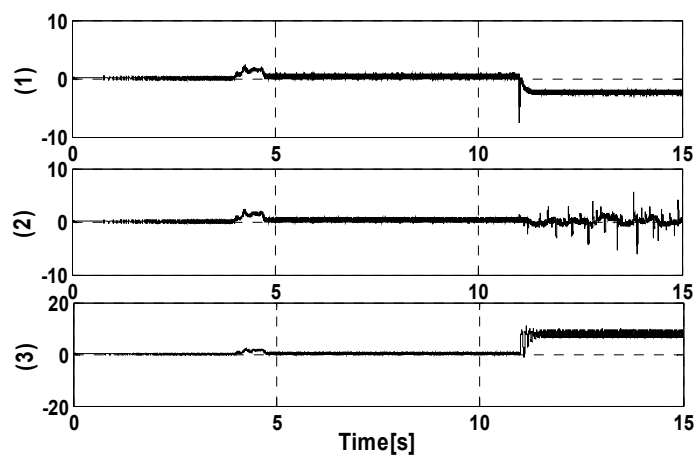

c)
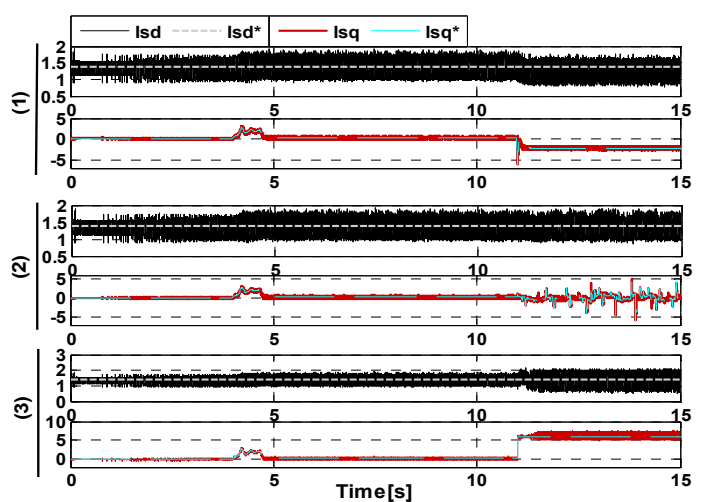

b)

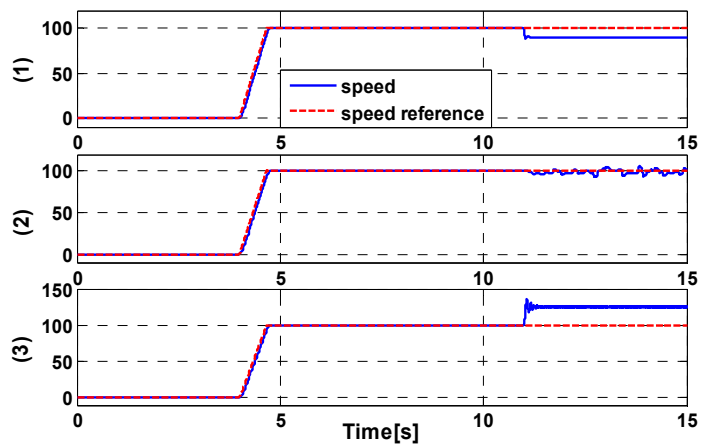

d)

Fig. 3 a) Phase current, b) Currents on "dq" reference frame, c) Torque, d) Speed. And from top to bottom for each subfigure; data plot corresponding to (1) offset fault, (2) uncertain measurement fault, (3) zero feedback fault.

\section{SPEED SENSOR FAULT DETECTION}

The detection of speed sensor faults is done in two steps:

- Sliding a window whose length is $20 \times$ (sampling time) which computes the average standard deviation of 20 points from the beginning of speed data by the following formula [23]:

$\overline{\sigma_{\Omega}}=\frac{\sum_{i=1}^{20} \sqrt{\left(\Omega_{i}-\overline{\Omega_{l}}\right)^{2}}}{20}$

- Faults produce impulses using formula (8), to turn these last into a constant or rising signal, their energy is calculated by formula (9):

$$
E\left(\overline{\sigma_{\Omega}}\right)=\int_{-\infty}^{+\infty}\left|\overline{\sigma_{\Omega}}\right|^{2} d t
$$

The same calculations are performed on the speed reference, then a residue is generated as follows:
Residue $=\left|E\left(\overline{\sigma_{\Omega}}\right)-E\left(\overline{\sigma_{\Omega^{*}}}\right)\right|$

When the residue exceeds a preset threshold, a fault detection signal goes from zero to one. The bloc scheme of the technique is represented by Fig. 4. To mask the effect of the transient stats and torque load, the average standard deviation signal is compared to a prior threshold to make only the faults signatures pass. Simulation of the technique on Matlab has given the results shown on Fig. 5. The residue stays in zero till the fault is applied, so the average standard deviation of the speed presents an impulse in the offset fault case Fig. 5a) and a series of impulses when the measurement is inaccurate or the speed signal is totally lost Fig. 5b), c). These signatures are transformed to a constant or rising signal by calculating their energy. Consequently, the residue exceeds the threshold which indicates the faulty state of the speed sensor. 


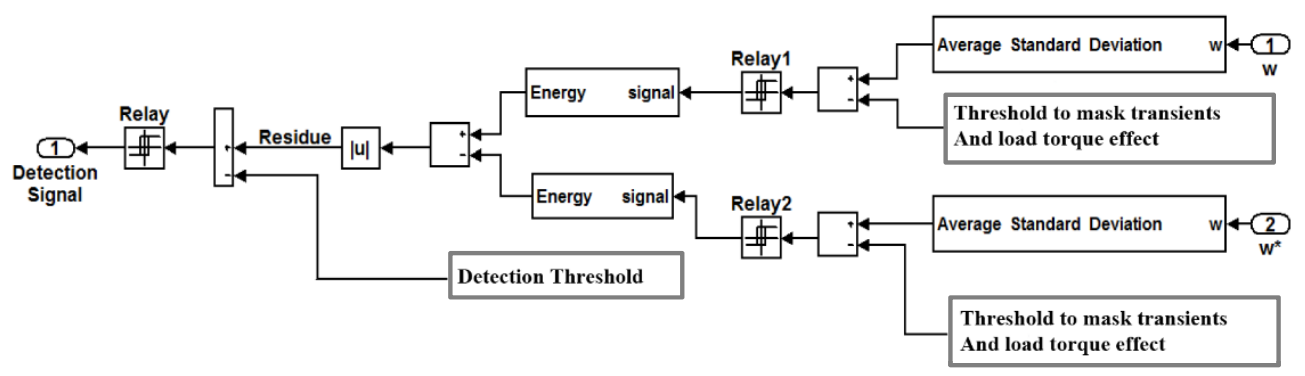

Fig. 4 Speed sensor fault detection scheme

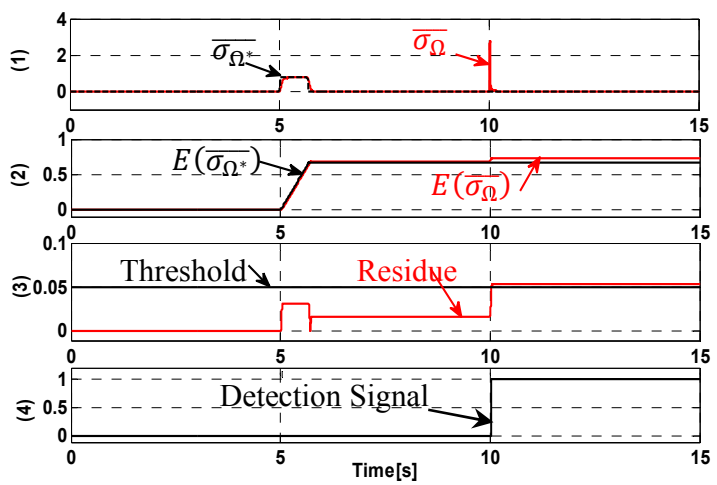

a)

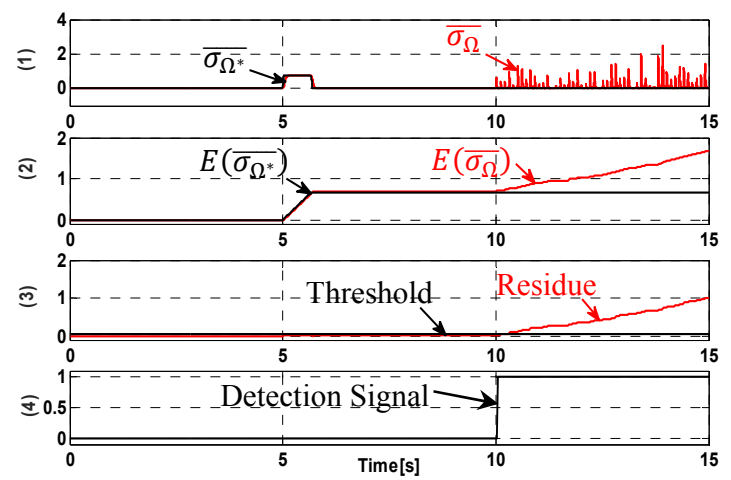

b)

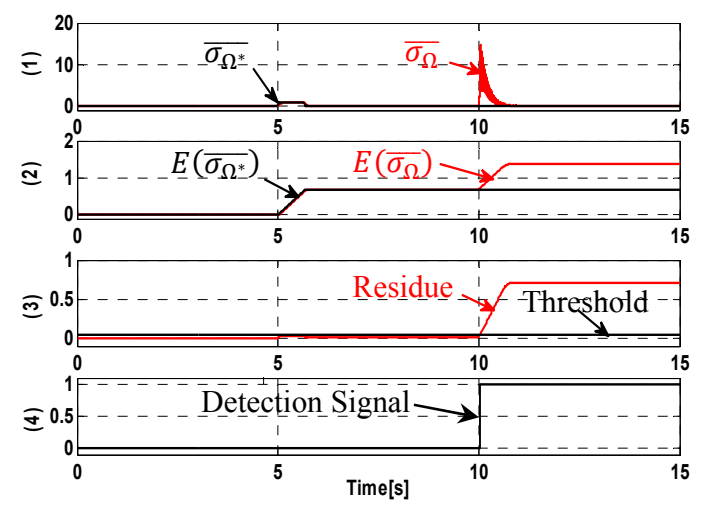

c)

Fig. 5 Detection results for: a) Offset fault, b) Uncertain measurement fault, c) Zero feedback fault. (1) Average standard deviation of speed and speed reference, (2) Energy of the average standard deviation of the speed and speed reference, (3) Residue and detection threshold, (4) Detection signal.

\section{EXPERIMENTAL VALIDATION}

To verify the simulation results, the same tests are carried out on an induction motor controlled via a Dsp1104. The experimental setup is illustrated in Fig. 6. Currents are measured using three LA25-NP transducers, and a tachometric generator is coupled to the shaft to measure the speed. All Faults are performed in the experiment similarly to the simulation. Fig. 7a), 7b), 7c) and 7d) represent successively phase current, three phase currents on "dq" reference frame, torque, rotor speed. We notice that the experimental figures are almost similar to those produced by simulation. The only difference is the noise due to measurement and the raise in speed response time. Faults detection is performed by the same scenario, where the residue represents the error between the energy of the average standard deviation of the speed and its reference. According to (Fig. 8), the experimental test proves the efficiency of the suggested detection scheme, since experimental results are almost similar to those of simulation. 


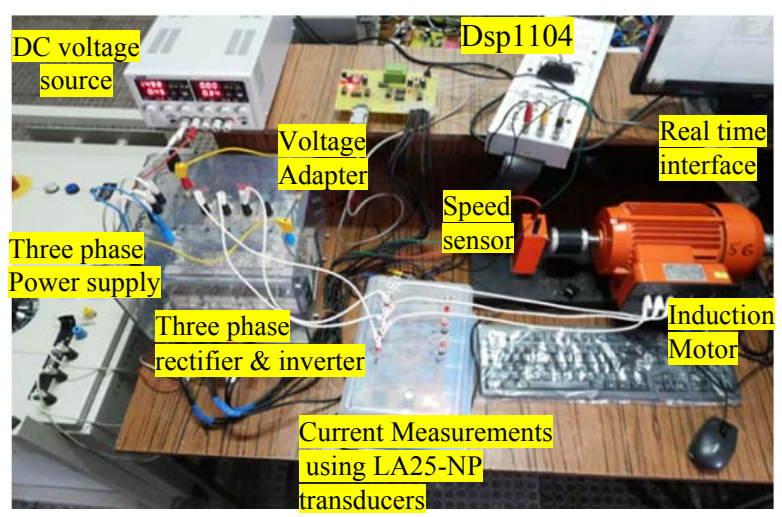

Fig. 6 Picture of the experimental setup

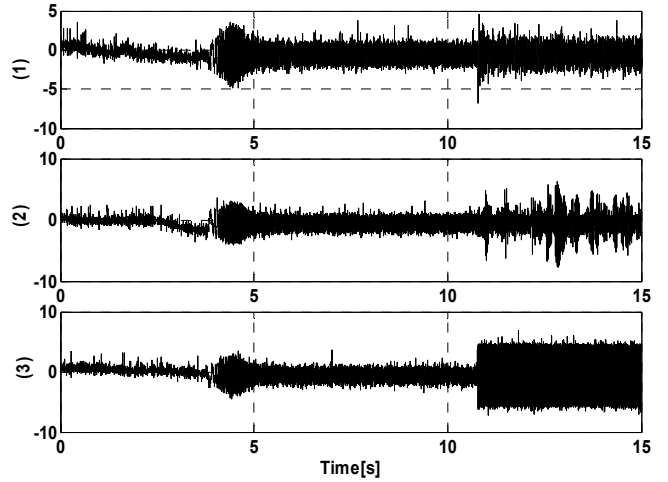

a)

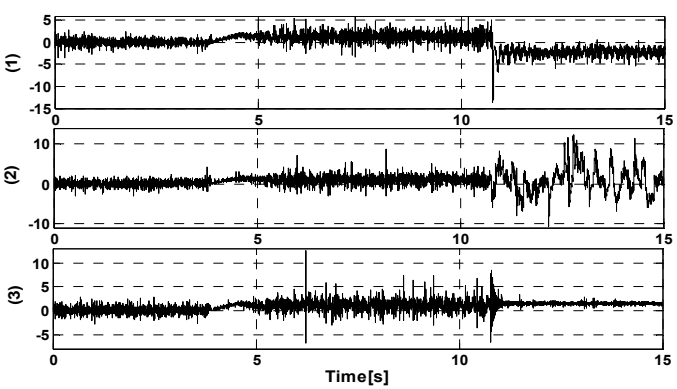

c)
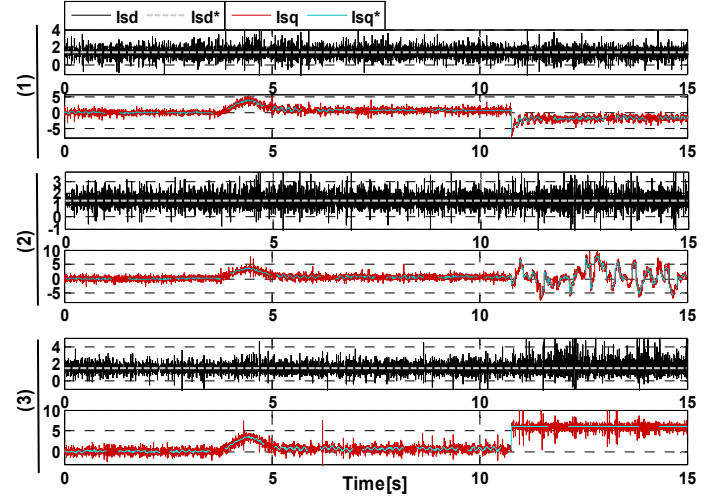

b)

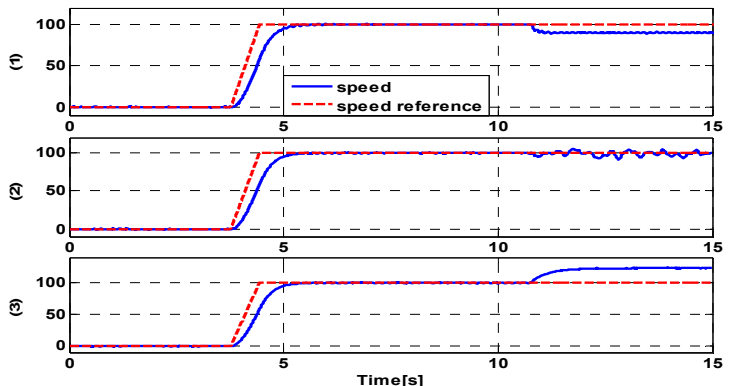

d)

Fig. 7 a) Phase current, b) Currents on "dq" reference frame, c) Torque, d) Speed. And from top to bottom for each subfigure; data plot corresponding to (1) offset fault, (2) uncertain measurement fault, (3) zero feedback fault.
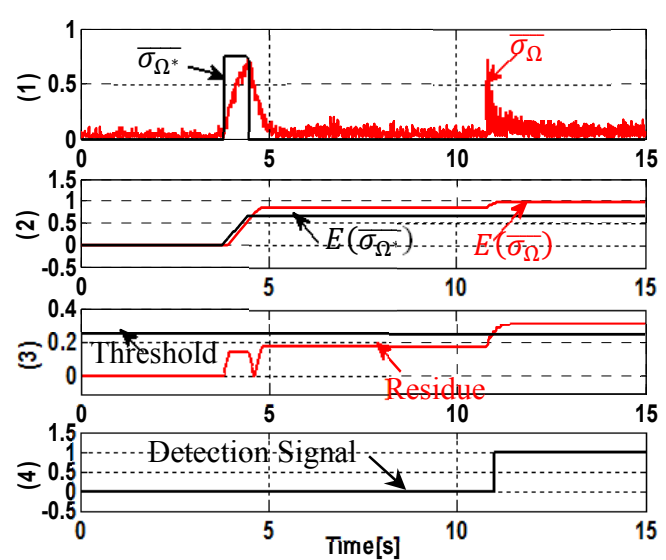

a)

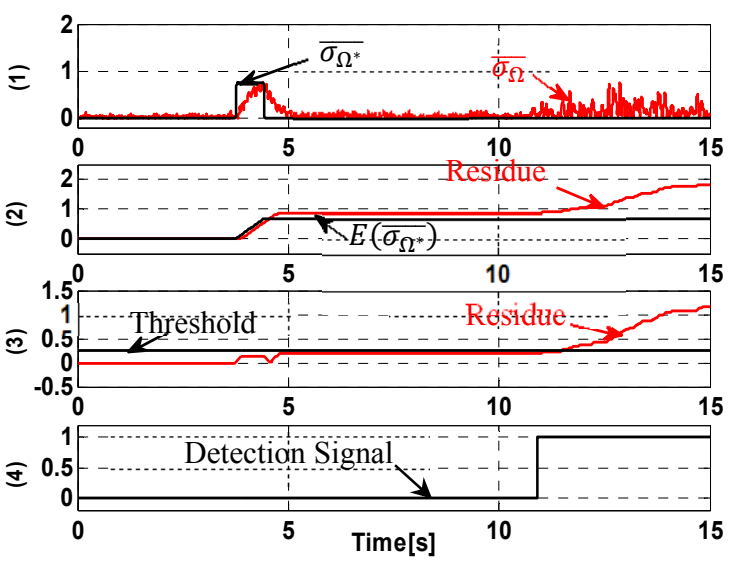

b) 


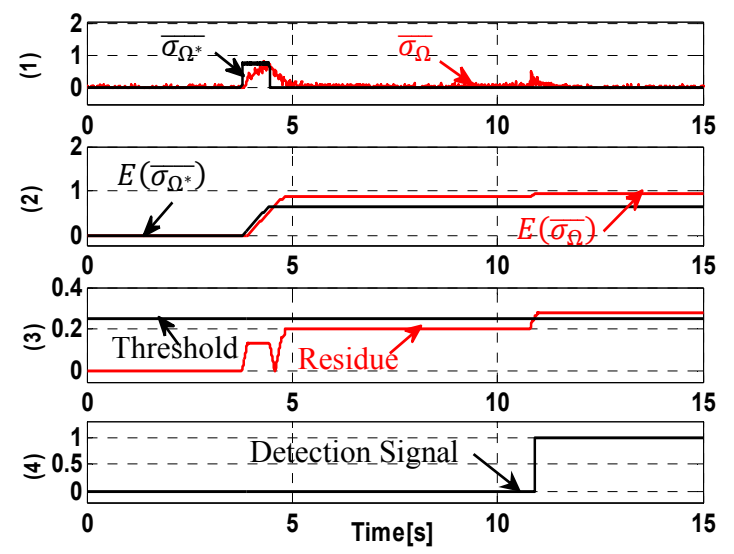

c)

Fig. 8 Detection results for: a) Offset fault, b) Uncertain measurement fault, c) Zero feedback fault. (1) Average standard deviation of speed and speed reference, (2) Energy of the average standard deviation of the speed and speed reference, (3) Residue and detection threshold, (4) Detection signal.

\section{VALIDATION WITH LOAD TORQUE AND VARIOUS SPEEDS}

To verify the validity of the proposed detection approach with load torque and variable speed, a simulation has been performed. In this section, only uncertain measurement fault is considered. Fig. 9 shows the fault effect on the different variables. From Fig. 10 we notice that the detection approach is still efficient under the load and with variable speed. In order to insure the robustness of the fault detector, the threshold to mask transient states and load effects (see Fig. 4) should be superior to the highest value of the average standard deviation generated by a load torque or variation in speed reference.

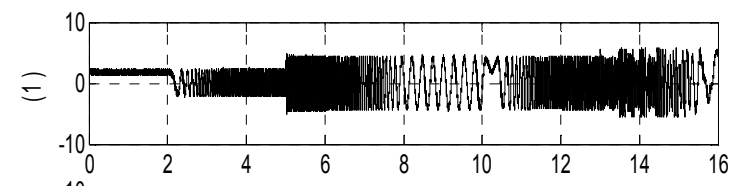

$\widetilde{\simeq}$
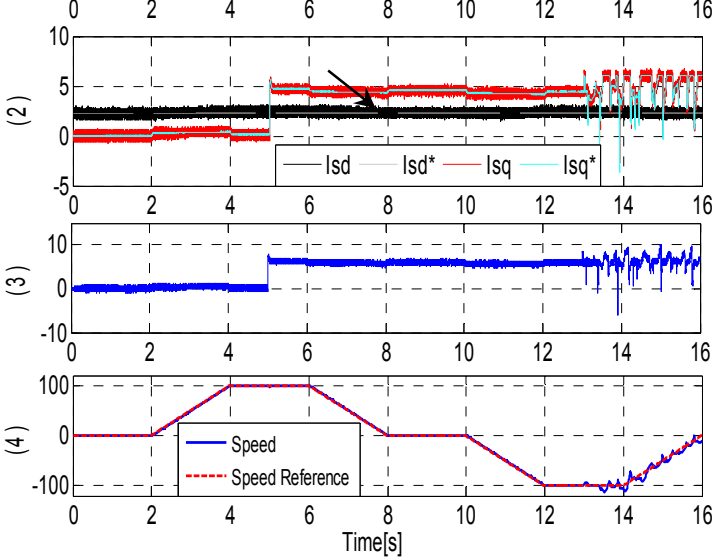

Fig. 9 The effect of uncertain measurement fault on: (1) Phase current, (2) Phase currents on dq reference frame, (3) Torque and Speed.

\section{CONCLUSION}

This paper has dealt with three types of speed sensor faults, offset, inaccurate measurement and the zero feedback fault. The effect of each one of them on the vector control of an induction motor is presented, then, a new detection scheme is proposed. Faults are basically detected by the calculation of the energy of the average standard deviation of the speed and its reference, then the two energies are compared in order to generate a fault detection signal.

The defective speed sensor has to be quickly isolated because it lowers the performance of the induction motor control, which leads to an enhanced type of control having a fault tolerance feature.

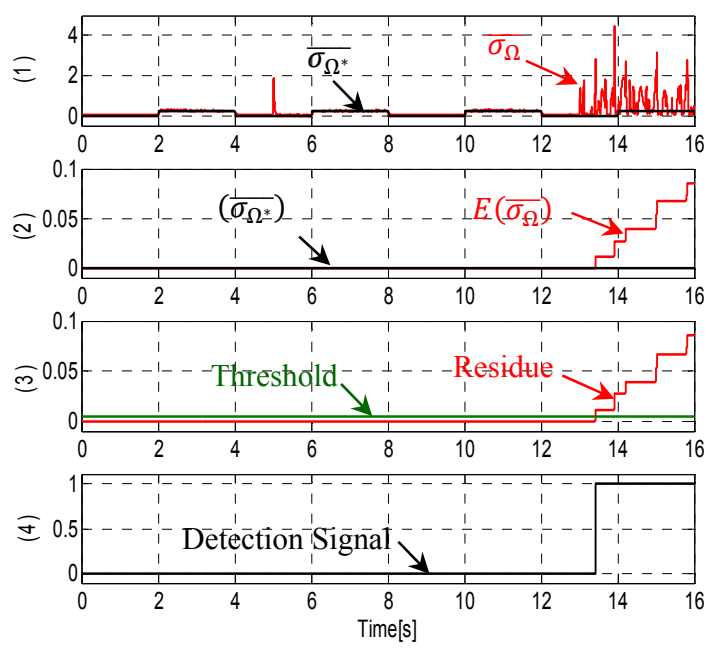

Fig. 10 Detection results for uncertain measurement fault, (1) Average standard deviation of speed and speed reference, (2)

Energy of the average standard deviation of the speed and speed reference, (3) Residue and detection hreshold, (4) Detection signal. 


\section{APPENDIX A: NOMENCLATURE AND SYMBOLS}

$v_{s d}, v_{s q} \quad$ Direct and Quadrature stator voltages.

$v_{s d}^{*}, v_{s q}^{*} \quad$ Decoupled, direct and Quadrature stator voltages.

$e_{d}, e_{q} \quad$ Coupling terms on d,q axes.

$v_{r d}, v_{r q} \quad$ Direct and Quadrature rotor voltages.

$i_{s d}, i_{s q} \quad$ Direct and Quadrature stator currents.

$i_{r d}, i_{r d} \quad$ Direct and Quadrature rotor currents.

$\phi_{r d}, \phi_{r d} \quad$ Direct and Quadrature rotor fluxes.

$\Omega, \Omega^{*} \quad$ Actual rotor speed, reference rotor speed.

$\Delta \Omega \quad$ Injected speed sensor fault.

$R_{s}, R_{r} \quad$ Stator resistance, rotor resistance.

$L_{s}, L_{r}, L_{m} \quad$ Cyclic rotor inductance, Cyclic rotor inductance, Cyclic mutual Inductance.

$\sigma \quad$ Leakage factor, $\sigma=1-\frac{L_{m}{ }^{2}}{L_{s} L_{r}}$.

$\omega_{e}, \omega_{s l} \quad$ Stator frequency, slip frequency.

$\theta_{e} \quad$ Angle that fulfills $\omega_{e}=\frac{d \theta_{e}}{d t}$.

$T_{e} \quad$ Electromagnetic torque.

$\phi_{r}{ }^{*} \quad$ Reference flux.

$p \quad$ Number of pole pairs.

$f \quad$ Motor friction coefficient.

J Inertia constant of motor.

$\tau_{m} \quad$ Motor mechanical time constant.

$\widetilde{\Omega_{F}} \quad$ Measured speed by the faulty sensor.

$\overline{\sigma_{\Omega}} \quad$ Speed average standard deviation.

$E\left(\overline{\sigma_{\Omega}}\right) \quad$ Energy of the average standard deviation.

\section{APPENDIX B: RATED DATA OF THE INDUCTION MOTOR}

Table 1 Rated data of the Induction Motor

\begin{tabular}{|l|l|l|l|}
\hline \multicolumn{2}{|l|}{ Rated values } & \multicolumn{2}{l|}{ Rated parameters } \\
\hline Voltage $(\Delta / \mathrm{Y})$ & $220 / 380[\mathrm{v}]$ & $R_{s}, R_{r}$ & $\begin{array}{l}12.75,5.1498 \\
{[\Omega]}\end{array}$ \\
& & & \\
\hline Current $(\mathrm{Y})$ & $2.7[\mathrm{~A}]$ & $L_{s}, L_{r}$, & $0.4991,0.4331$, \\
& & $M$ & $0.4331[\mathrm{H}]$ \\
\hline Power & $0.9[\mathrm{~kW}]$ & $J$ & $0.0035\left[\mathrm{~kg} \cdot \mathrm{m}^{2}\right]$ \\
\hline Pole pairs $(p)$ & 2 & $f$ & $0.001[\mathrm{Nm} / \mathrm{rd} / \mathrm{s}]$ \\
\hline
\end{tabular}

\section{REFERENCES}

[1] HEREDIA, G. - OLlERO, A. - BEJAR, M. MAHTANI, R.: Sensor and actuator fault detection in small autonomous helicopters, Mechatronics, Vol. 18, No. 2, 2008, pp. 90-99.

[2] SCELBA, G. - DE DONATO, G. - SCARCELLA, G. - GIULII CAPPONI, F. - BONACCORSO, F.: Fault-tolerant rotor position and velocity estimation using binary hall-effect sensors for low-cost vector control drives, IEEE Transactions on Industry Applications, Vol. 50, No. 5, 2014, pp. 3403-3413.

[3] RAISEMCHE, A. - BOUKHNIFER, M. LAROUCI, Ch. - DIALLO, D.: Two Active Fault Tolerant Control Schemes of Induction Motor Drive in EV or HEV, IEEE Transactions on Vehicular Technology, Vol. 63, No. 1, 2014, pp. 19-29.

[4] SILVA, J. C. - SAXENA, A. - BALABAN, E. GOEBEL, K.: A knowledge-based system approach for sensor fault modeling, detection and mitigation, Expert Systems with Applications, Vol. 39, No. 12, 2012, pp. 10977-10989.

[5] TABBACHE, B. - BENBOUZID, M. - KHELOUI, A. - BOURGEOT, J. M.: DSP-based sensor faulttolerant control of electric vehicle powertrains. Proceedings - ISIE: IEEE International Symposium on Industrial Electronics, No. 3, 2011, pp. 20852090 .

[6] DUAN, S. - LI, Q. - ZHAO, Y.: Fault diagnosis for sensors of aero-engine based on improved least squares support vector regression, Eighth International Conference on Fuzzy Systems and Knowledge Discovery (FSKD), Vol. 3, 2011, pp. 1962-1966.

[7] CHELliaH, T. R. - DOMINIC, A. THANGARAJ, R.: Analysis of induction motor drives under sensor faults with mine hoist load diagram, Proceedings of the International Conference on Power Electronics and Drive Systems. Sydney, NSW, 2015, pp. 274-277.

[8] JAYAKUMAR, M. - DAS, B. B.: Fault detection, isolation and reconfiguration in presence of incipient sensor faults in an electromechanical flight control actuation system, Proceedings of the IEEE International Conference on Industrial Technology, 2006, pp. 92-97.

[9] NAJAFABADI, T. A. - SALMASI, F. R. JABEHDAR-MARALANI, P.: Detection and isolation of speed-, DC-link voltage-, and currentsensor faults based on an adaptive observer in induction - motor drives, IEEE Transactions on Industrial Electronics, Vol. 58, No. 5, 2011, pp. 1662-1672. 
[10] TABBACHE, B. - BENBOUZID, M. E. H. KHELOUI, A. - BOURGEOT, J.: Virtual-SensorBased Maximum-Likelihood Voting Approach for Fault-Tolerant Control of Electric Vehicle Powertrains, IEEE Transactions on Vehicular Technology [online], Vol. 62, No. 3, 2013, pp. 10751083.

[11] DYBKOWSKI, M. - KLIMKOWSKI, K. ORLOWSKA-KOWALSKA, T.: Speed Sensor Fault Tolerant Direct Torque Control of Induction Motor Drive, In: 16th International Power Electronics and Motion Control Conference and Exposition, Antalya, Turkey, 2014, pp. 679-684.

[12] de PliNVAL, H. - BURLION, L.: Sensor Fault Detection and Estimation for Quadrotors Using Kinematic Equations, Advances in Aerospace Guidance, Navigation and Control [online], 2011, pp. 287-301.

[13] DAMDOUM, A. - BERRIRI, H. - SLAMABELKHODJA, I.: Detection of faulty incremental encoder in a DFIM-based variable speed pumpturbine unit, Proceedings of the Mediterranean Electrotechnical Conference - MELECON, 2012, pp. 1151-1154.

[14] KLIMKOWSKI, K. - DYBKOWSKI, M.: A Comparative Analysis of the Chosen Speed Sensor Faults Detectors for Induction Motor Drives, In: IEEE International Conference on Electrical Drives and Power Electronics (EDPE), 2015, pp. 21-23.

[15] BOUROGAOUI, M. - JLASSI, I. - EL KHIL, S. K. - BEN ATTIA SETHOM, H.: An effective encoder fault detection in PMSM drives at different speed ranges, Proceedings - SDEMPED 2015: IEEE 10th International Symposium on Diagnostics for Electrical Machines, Power Electronics and Drives, 2015, pp. 90-96.

[16] CHAKRABORTY, C. - VERMA, V.: Speed and Current Sensor Fault Detection and Isolation Technique for Induction Motor Drive Using Axes Transformation, Industrial Electronics, IEEE Transactions on, Vol. 62, No. 3, 2015, pp. 19431954.

[17] LEE, J. - PARK, C. G.: Cascade filter structure for sensor/actuator fault detection and isolation of satellite attitude control system, International Journal of Control, Automation and Systems, Vol. 10, No. 3, 2012, pp. 506-516.

[18] TABBACHE, B. - KHELOUI, A. - BENBOUZID, M. E. H. - MAMOUNE, A. - DIALLO, D.: Research on Fault Analysis and Fault-Tolerant Control of EV/HEV Powertrain, In: First International Conference on Green Energy ICGE, Sfax. IEEE, 2014. pp. 284-289.
[19] CHOI, C. - LEE, K. - LEE, W.: Observer-based phase-shift fault detection using adaptive threshold for rotor position sensor of permanent-magnet synchronous machine drives in electromechanical brake, IEEE Transactions on Industrial Electronics, Vol. 62, No. 3, 2015, pp. 1964-1974.

[20] ALKAYA, A. - EKER, I.: Luenberger observerbased sensor fault detection: Online application to DC motor, Turkish Journal of Electrical Engineering and Computer Sciences, Vol. 22, No. 2, 2014, pp. 363-370.

[21] GAID, K. S. - PING, H. W. - UDDIN, M. N. KHALID, M. - SAGHAFINIA, A.: Wavelet Based Prognosis for Fault Tolerant Control of Induction Motor with Stator and Speed Sensor Faults, In: Industry Applications Society Annual Meeting (IAS), IEEE, 2012, pp. 1-8.

[22] GOLABI, S. - BABAEI, E. - SHARIFIAN, M. B. B. - GOLABI, Z.: Application of Speed, Rotor Flux, Electromagnetic, Load Torque Observers and Diagnostic System in a Vector-Controlled HighPower Traction Motor Drive, Arabian Journal for Science and Engineering, Vol. 39, No. 4, 2014, pp. 2979-2996.

[23] SEPE, R. B. - MORRISON, C. - MILLER, J. M.: Fault-Tolerant Operation of Induction Motor Drives with Automatic Controller Reconfiguration, Practical Failure Analysis, Vol. 3, Issue 1, February 2003, pp. 64-70.

[24] WANG, H. - PEKAREK, S. - FAHIMI, B.: Multilayer control of an induction motor drive:A strategic step for automotive applications, IEEE Transactions on Power Electronics, Vol. 21, No. 3, 2006, pp. 676-686.

[25] KIM, Ki-Chan - HWANG, Su-Jin - SUNG, KiYoung - KIM, YeongSik: A study on the fault diagnosis analysis of variable reluctance resolver for electric vehicle, Proceedings of IEEE Sensors, 2010, pp. 290-295.

[26] PAEK, Sung-Kuk, PARK, Byeong-Cheol - NOH, Myoung-Gyu D.: Design of fault-tolerant inductive position sensor, Proceedings of the IEEE International Conference on Control Applications, October 2007, pp. 617-621.

[27] LI, Jianming - ZHOU, Jinglun - YU, Zhiyuan ZHU, Xiaorong: Dual-Fault Tolerant Control Method of Feedback Loop for Permanent Magnet Synchronous Motor, In: IEEE International Conference on Mechatronics and Automation (ICMA), Beijing, 2015, pp. 459-463.

[28] CHAKRABORTY, Ch. - VERMA, V.: Speed and current sensor fault detection and isolation technique for induction motor drive using axes transformation. 
IEEE Transactions on Industrial Electronics, Vol. 62, No. 3, 2015, pp. 1943-1954.

[29] ACHIRICA, R. - BOSQUE, G.: Position and speed sensor fault tolerant sinusoidal PWM drive for Permanent Magnet Synchronous Motor, Conference on Control and Fault-Tolerant Systems, SysTol. 2013, pp. 764-771.

[30] WU, Zhong-Qiang - YANG, Yang - XU, ChunHua: Adaptive fault diagnosis and active tolerant control for wind energy conversion system, International Journal of Control, Automation and Systems [online], Vol. 13, No. 1, December 2014, pp. 120-125.

[31] SKÓRA, M. - KOWALSKI, T.: The Influence of Sensor Faults on PM BLDC Motor Drive, 2015, pp. 21-23.

[32] LISHUANG, Xu - TAO, Cai - FANG, Deng - XIN, Liu: The research of sensor fault diagnosis based on genetic algorithm and one-against-one support vector machine, 2nd International Conference on Intelligent Control and Information Processing, Vol. 2, 2011, pp. 808-812.

[33] MAHMOOD, Z and KHATTAK, N S. Fault Diagnostics of Rotating Machinery, 2011 21st International Conference on Systems Engineering, 2011, pp. 64-69.

[34] TAHAMI, F. - SHOJAEI, A. - KHATIR, D. A.: A Diversity Based Reconfigurable Method for Fault Tolerant Control of Induction Motors, In: IEEE International Symposium on Power Electronics, Electrical Drives, Automation and Motion, 2006, pp. 12-17.
[35] ZIDANI, F. - DIALLO, D. - BENBOUZID, M. E. H. - BERTHELOT, E.: Diagnosis of speed sensor failure in induction motor drive, Proceedings of IEEE International Electric Machines and Drives Conference, IEMDC 2007, 2007, Vol. 2, pp. 16801684.

Received December 14, 2016, accepted March 17, 2017

\section{BIOGRAPHIES}

Mohamed Bouakoura was born in Batna, Algeria. He received his M.Sc. degree in Control and Diagnosis of Electrical Systems in 2014 from the University of Batna 2. He is currently pursuing his Ph.D. studies at the same university. His research theme is the diagnosis and FTC of induction motor drives.

Nasreddine Nait-Said was born in Batna, Algeria. He received his M.Sc. degree in Industrial Electricity in 1993 and $\mathrm{Ph} . \mathrm{D}$. degree in electrical engineering from the University of Batna, Algeria in 2003. Currently, he is a Full Professor at the Electrical Engineering Department, University of Batna 2. His research interests include application of AI techniques and control in the field of electrical machines.

Mohamed-Said Nait-Said was born in Batna, Algeria. He received his M.Sc. in Electrical and Computer Engineering from the Electrical Engineering Institute of Constantine University, Algeria, in 1992. He received his Ph.D. degree in Electrical and Computer Engineering from the University of Batna in 1999. Currently, he is a Full Professor at the Electrical Engineering Department, University of Batna 2. His research interests include electric machines, drives control and diagnosis. 